\title{
Prevalence of Headache in Female Students in King Faisal University: A Questionnaire Study
}

\author{
Eman Salman Al-Hassan ${ }^{1}$, Amani Ali Al-Mulifi' ${ }^{2}$ Abrar Mohammed Al-Khudhayr ${ }^{3}$, \\ Amjad Wahab Al-Quraini ${ }^{4}$, Asma'a Mohammed Al-Omran ${ }^{5}$, Eman Jawad Al-Musallam6, \\ Batool Abdullah Al-Rashed ${ }^{7}$, Doa'a Ali Al-Mubarak ${ }^{8}$, Huda'a Murtadha Al-Yousof', \\ Khadija Radhi Al-Khalifa ${ }^{10}$, Zainab Salman Al-Obaid1 ${ }^{1}$, Sayed Ibrahim Ali ${ }^{12}$, Aneela Khalid ${ }^{13}$ \\ ${ }^{1}$ Medical students at King Faisal University, College of Medicine, Saudi Arabia \\ ${ }^{12,13}$ King Faisal University, College of Medicine, Saudi Arabia
}

\begin{abstract}
Background: Headache is the most common neurological disorder. Almost half of the adults all around the world experience one or more of all types of headache (Tension-type and migraine are the most common types of primary headache). Aim: to evaluate the prevalence of headache among female students in King Faisal University. Methodology: This study was a cross-sectional, questionnaire -based conducted among students of different colleges during the months between Octobers to December, 2013. The data was collected from 100 female students in KFU. Results: A total of 100 female students were evaluated. The prevalence of headache was $77 \%$, (58.4\% migraine type and $41.6 \%$ tension type headache, $(p<0.05)$ A positive family history was found in $71.1 \%$ of students. Stress, too little sleep, changing of mode and menstrual cycle were reported as higher prevalence in student with headache.64.9percentage of students was using medication. Conclusion: The results demonstrated that prevalence of headache is high among female students in KFU. Migraine was the most common type, stress and too little sleep might be significant factors in prevalence of headache. Further multicenter studies would be necessary to evaluate headache epidemiology among
\end{abstract}

Keywords: Tension-type, migraine, primary headache.

\section{Introduction}

Headache is the most common neurological disorder (8). Almost half of the adults all around the world experience one or more of all types of headache (1). Globally, it affects 50$75 \%$ of adult's aged $18-65$ at least once a year. $(1,8)$.

Most of headache cases are primary which occur incidentally and are not caused by any other medical condition. Primary headache is a cascade of events that affects blood vessels and nerves inside and outside the head which causes pain signals to be sent to the brain. Brain chemicals called neurotransmitters are involved in creating head pain, as they create changes in nerve cell activity (10).

The causes of headache may be related to age, gender, health and lifestyle. Results from a cross-sectional study in Germany, showed that headache was higher in female, physically inactive and smokers than the others (3) and the unpredictable nature of it may affect the lifestyle and decrease the productivity of individuals at work(9).

Tension-type and migraine are the most common types of primary headache. According to statistical study done by WHO, $80 \%$ of people complained of tension-type headache and more than $10 \%$ were reported as migraine's cases $(1,8)$.

Migraine is a complex disorder characterized by recurrent episodes of headache. It is usually unilateral pain and may be associated with visual or sensory symptoms (collectively known as an aura) that arise most often before the head pain but that may occur during or afterward(11), while tension headache causes dull pain impact the whole head and it begins in the back of the head or above the eyebrows. This type can be caused by the neuronal and chemical disruption on the brain and it may be related to muscle tightening in the back of the neck or scalp (2).

In fact college students usually at high risk for headache attack. All types of headache may be seen among them in different frequencies (5). According to study conducted in Gaziosmanpasa University in Turkey, $41.02 \%$ of students complained of headache with its different types, but tensiontype is the most common, and some of them may complain migraine (4).

Students' life style set them at high risk to suffer from stress, fatigue and anxiety which are the most common causes of tension-type headache and migraine because of:

1)Spending a long time on an uncomfortable position either in the classes or in the table when they study or do their assignments.

2) Reading in textbooks with very small-font.

3) Spending many hours staring at computers screens.

4)Inadequate sleeping hours.

So, it won't be surprised to see these types of headache present in them (5).

Regarding to study done in University of São Paulo in Brazil, college students were surveyed for characteristics of migraine or tension-type headache. $25 \%$ experienced migraines and $32.9 \%$ reported tension headaches (12).

Also, according to study conducted in An-Najah National University in Palestine, $95.2 \%$ of Pharmacy students complained of different types of headache, $40 \%$ of them had family history. $78.2 \%$ of students reported stress as most common triggering factor. $79.1 \%$ reported self- therapy while 


\section{International Journal of Science and Research (IJSR) \\ ISSN (Online): 2319-7064}

Index Copernicus Value (2013): 6.14 | Impact Factor (2015): 6.391

$20.9 \%$ didn't use any medication in the headache episodes (13).

Medical students in university of Nigeria were surveyed by using questionnaire to ascertain frequency and pattern of primary headaches. $88.3 \%$ of the students complained of one year Frequency headache, $18.1 \%$ had migraine, $36.8 \%$ tension-type and $17 \%$ chronic daily headache(7).

Also, there is another study conducted at medical sciences students Isfahan University to evaluate the prevalence and the associated factors of headache. The results showed, $58.7 \%$ of students complained headache, $14.2 \%$ were reported as migraine and $44.2 \%$ as tension-type (6).

According to the study conducted in a medical college in South India, $68 \%$ of students had headache. $42 \%$ fulfilled the criteria for migraine and $57 \%$ had other forms of headache (14).

Regarding study on University of Caxias do Sul on Brazil,of all undergraduate students interviewed, $74.5 \%$ had at least one headache episode in the last three months (15).

Other study was conducted in high school students in Riyadh. They found, the highest prevalence rate of headache $(35.8 \%)$ occurring among those aged (20-21 years). In $88 \%$ of adolescents, $74 \%$ had pulsating pain, $58 \%$ had unilateral pain and $80 \%$ had nausea (16).

From the above studies, we expected that Female students in KFU may have headache in high percentages. The aim of this study was to show the prevalence of headache among Female students of KFU, then make a comparison between the prevalence of tension-type and migraine among colleges students.

\section{Methodology}

\section{A. Population Study}

This study was a cross-sectional, questionnaire -based which conducted among students of different colleges and carried out during months between October to December, 2013. The study area was KFU in SA and the study sample was 100 female students from10 different colleges.

\section{B. Study Tool: The Questionnaire.}

In the research, the data was collected by using a questionnaire which applied in KFU students and was designed with open-end and close-end question and divided into four sections. The first one was the demographic section which contained questions regarding (age, gender and college), family history of headaches, and question about student experience of any type of headache episodes in previous 6 months, duration and frequency of headache. The second was used to assess the quality, severity, and symptoms related to different types of headache with possible answers including: always, often, rare and never. The third was contained yes Ino questions about the causes of headache. Finally, medication or other ways used to control headache are in the fourth section.

\section{Collection of Data}

Data was collected by mean of questionnaire written in papers with traits as described above. The questionnaire was done under the supervision of a Pharmacologist. Questionnaire copies were answered completely and recollected again to be used in data analysis.

\section{Data Analysis}

All data were coded and then analyzed by using IBM SPSS statistics 19 . P-values < 0.05 was accepted as statistically Significant. The frequency and contingency tables were used for categorical variable.

\section{E. Ethical Considerations}

The consent has been obtained from KFU, college of medicine, department of family and community medicine. The participants were informed about the purpose of the study by providing them short paragraph at the beginning of the questionnaire. They were volunteers and the security of their information was ensured

\section{Results}

In the study, 100 female students were surveyed by questionnaire, 10 students from each of these 10 colleges (agriculture, applied studies, arts, business, computer, education, medical science, medicine, pharmacy and science). The average age of the students was (20.7) years (range, 19-24 years). 23 students (23\%) of sample were excluded because they didn't complain headache in previous 6 months and 77 students $(77 \%)$ had headache.

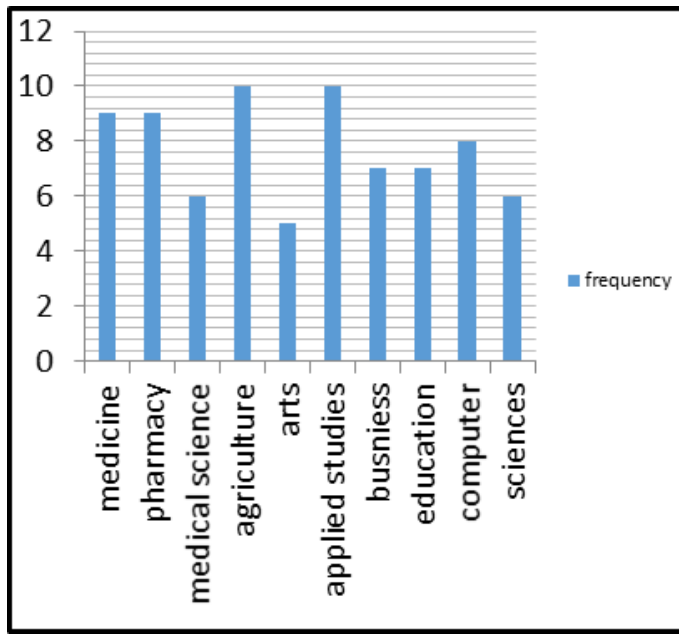

Chart 1: Frequency of headache among college's female students

The above chart show significant difference p-value $(<0.05)$ among different colleges. Following the chart, the majority of cases appear in certain colleges in comparing to the others.

The questionnaire reported $64.93 \%$ of headache cases family history, while $35.06 \%$ were without.

In comparing duration of different types of headache episodes, there is no significant difference ( $p$-value $>0.05$ ) between tension-type and migraine. 


\section{International Journal of Science and Research (IJSR) \\ ISSN (Online): 2319-7064 \\ Index Copernicus Value (2013): 6.14 | Impact Factor (2015): 6.391}

Table 1: Frequency and percentage of headache episodes duration

\begin{tabular}{|c|c|c|c|}
\hline Duration & $\begin{array}{c}\text { No. of effected } \\
\text { students }\end{array}$ & Percentage & $\begin{array}{c}\text { P } \\
\text { value }\end{array}$ \\
\hline 1-4 hours & 24 & $31.17 \%$ & $>0.05$ \\
\cline { 1 - 2 } 4-12 hours & 25 & $32.47 \%$ & \\
\cline { 1 - 2 } 12-24 hours & 26 & $33.77 \%$ & \\
\cline { 1 - 2 } 24-72 hours & 2 & $2.60 \%$ & \\
\hline
\end{tabular}

In all affected students, $53.25 \%$ of them had frequent headache episodes (>2 episodeslmonth), and the other $46.75 \%$ were reported that they their headache episodes occur infrequently ( $<1$ episodelmonth).

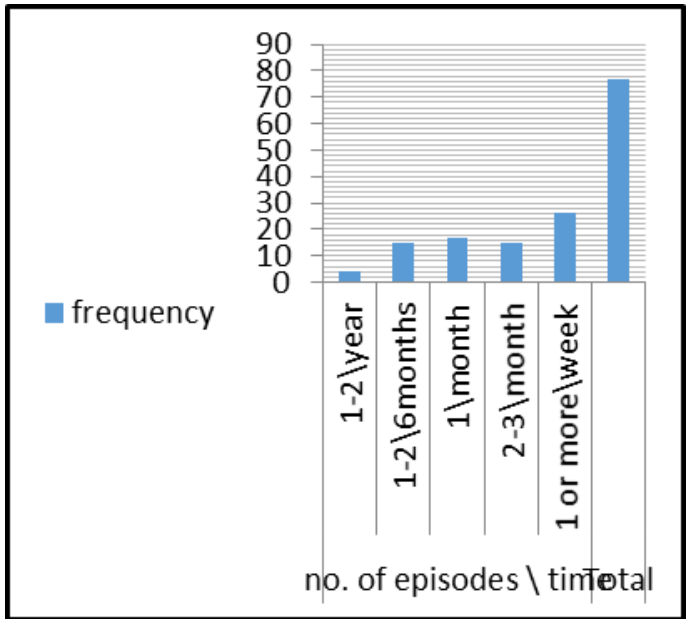

Chart 2: Frequency of students with different number of episodes.

Regarding to the number of headache episodes, there is significant difference ( $p$-value $<0.05$ ) between ages of students while type of colleges didn't showed any significant difference ( $p$-value $>0.05$ ).

Regarding to the symptoms of headache, pulsing and throbbing, unilateral pain,nausea and sensitivity to noise showed significant difference ( $p$-value $<0.05$ ) between tension-type and migraine while the others didn't show significant difference ( $\mathrm{p}$-value $>0.05$ ).

According to data analysis, there is significant difference ( $\mathrm{p}$ value <0.05) in stress, too little sleep, missed meal and menstrual cycle while the others didn't show any difference ( $\mathrm{p}$-value $>0.05$ )

Table 2: Percentage of headache symptoms in students with frequents episodes

\begin{tabular}{|c|c|r|}
\hline Symptoms & Percentage & P value \\
\hline Need to lying in dark room & $88.31 \%$ & $<0.05$ \\
\hline Phonophobia & $85.71 \%$ & \\
\hline Pulsing, throbbing pain & $67.53 \%$ & \\
\hline Avoiding of daily activity & $67.53 \%$ & \\
\hline Unilateral pain & $62.34 \%$ & \\
\hline Moderate to severe pain & $59.74 \%$ & \\
\hline Photophobia & $46.75 \%$ & \\
\hline Pain in moving, bending & $45.45 \%$ & \\
\hline Visual disturbance & $40.26 \%$ & \\
\hline Nausea & $28.57 \%$ & \\
\hline
\end{tabular}

From 77 students who had headache episodes, it was noticed that $32(41.6 \%)$ students were reported with tension-type headache and $45(58.4 \%)$ were with migraine.

Regarding to type of headache attack, there is significant difference ( $p$-value <0.05) among different colleges students.

Depending on questionnaire, $46.67 \%$ of migraine cases were reported with aura, while the other $53.33 \%$ were without aura.

Table 3: Frequency of tension-type headache and migraine among college's female students

\begin{tabular}{|c|c|c|c|}
\hline \multirow{2}{*}{ College } & \multicolumn{2}{|c|}{ Diagnosis } & \multirow{2}{*}{ Total } \\
\cline { 2 - 3 } & tension & migraine & \\
\hline - Medicine & 3 & 6 & 9 \\
\hline - Pharmacy & 6 & 3 & 9 \\
\hline Medical Sciences- & 4 & 2 & 6 \\
\hline - Agriculture & 3 & 7 & 10 \\
\hline - Arts & 4 & 1 & 5 \\
\hline - Applied studies & 1 & 9 & 10 \\
\hline Business- & 5 & 2 & 7 \\
\hline - Education & 0 & 7 & 7 \\
\hline - Computer & 2 & 6 & 8 \\
\hline - Sciences & 4 & 2 & 6 \\
\hline Total & 32 & 45 & 77 \\
\hline
\end{tabular}

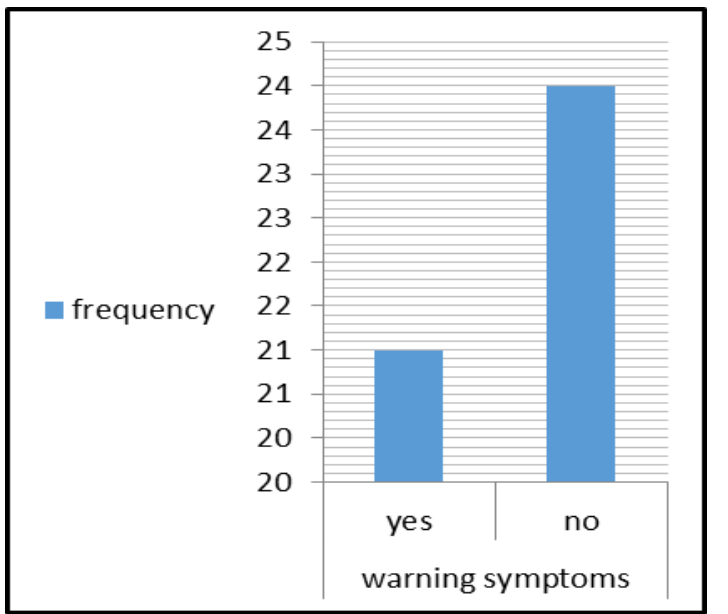

Chart 3: Frequency of migraine cases with and without aura

There is significant difference ( $\mathrm{p}$-value >0.05) between different colleges's students and getting migraine with or without aura.

When the students were asked about what they did when they had headache episode, $64.9 \%$ of students were using medications and the most common one was paracetamol, while $31.2 \%$ didn't use medications but just take a rest. Little of them about $1.3 \%$ going to clinic and the other $2.6 \%$ were using herbal medication. 


\section{International Journal of Science and Research (IJSR) \\ ISSN (Online): 2319-7064}

Index Copernicus Value (2013): 6.14 | Impact Factor (2015): 6.391

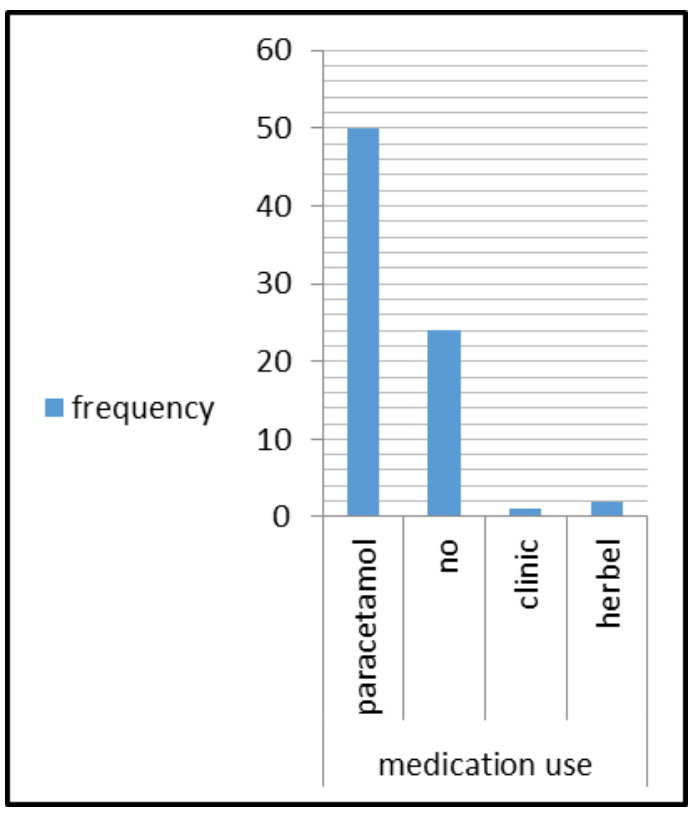

Chart 4: Frequency of medication use among colleges's female students.

In comparing different colleges' students, there is no significant difference ( $\mathrm{p}$-value $>0.05$ ) in the type of medications they used.

\section{Discussion}

The population sample was 100 students equally distributed among 10 colleges of KFU and data were collected by questionnaire and were designed with open-end and closeend question and divided into four sections. First section questions decided whether the students complain of headache or not. Out of 100 participants, 23 didn't fill the criteria of headache and were excluded.

The results reported high percentage of headache attack among female students. It was $77 \%$ in comparing with study done in Gaziosmanpasa University in Turkey that reported $41.02 \%$ of students experienced headache(4).

Nausea was reported as the least common symptom, it was $28.57 \%$ while in study done in high school students in Riyadh(16), it was reported about $80 \%$.

Data analysis showed the most common triggering factors which were stress $(93.51 \%)$, too little sleep $(90.91 \%)$, using computer for long time $(83.12 \%)$, changing of mood (71.43\%). The previous factors explained the high percentage of headache attack in colleges' students. Exams days, prolonged study and spending many hours inside classes with uncomfortable chairs or inadequate light in addition to multiple assignments which force students to spend many hours working in computer. All that may initiate the stress which was the most common associated factor related to headache.

The data showed, paracetamol was the most popular analgesic used by students to self-treat headache episodes. Also using of herbs to relive headache pain was about $3 \%$. It was lower than another study done in An-Najah National
University In Palestine which recorded $10.2 \%$ of using this type of medications primarily for the treatment of headache (13).

\section{Conclusion}

This research reported the large prevalence of headache among female students in KFU. Regarding the affected students, large number of them had family history of headache attack. In most cases, the number of headache episodes was 1 or morelweek and the duration were reported between12-24 hours. Migraine was the most common type of headache and most cases of it were reported without aura.

Regarding to the symptoms, pulsating, throbbing pain, phonophobia and need to lay in dark room were the most common. Questionnaire also recorded the most common triggering factors which were stress, too little sleep, using computer for long time, changing of mood and intense light or noise. They should be always evaluated for these factors.

Majority of students took paracetamol during headache episodes while other students didn't use any medication and too little went to clinic or used herbal medications.

\section{References}

[1] Danette C. Taylor, DO, MS, FACN. Tension Headaches [Internet] [cited 2013 Oct 2]. Available from: http://www.medicinenet.com/script/main/mobileart.asp? articlekey $=42071 \&$ page $=3$.

[2] Lehmann S, Milde-Busch A, Straube A, von Kries R, Heinen F. How specific are risk factors for headache in adolescents? Results from a cross-sectional study in Germany. Neuropediatrics. 2013 Feb;44(1):46-54. doi: 10.1055/s-0032-1333432. Epub 2013 Jan 10.

[3] Causes of Headaches in College Students [Internet]. 2009 Oct 8 [cited 2013 Oct 2]. Available from: http://www.headaches.org/blog/causes-headachescollege-students.

[4] Ezeala-Adikaibe AB, Stella EO, Ikenna O, Ifeoma U. Frequency and pattern of headache among medical students at Enugu, South East Nigeria. Niger J Med. 2012 Apr-Jun[cited 2013 Oct 2];21(2):205-Available from:http://www.ncbi.nlm.nih.gov/pubmed/23311192

[5] Smitherman TA, McDermott MJ, Buchanan EM. Negative impact of episodic migraine on a university population: Quality of life, functional impairment, and comorbid psychiatric symptoms. Headache. 2011 Apr;51(4):581-9. 4610.2011.01857.x doi:10.1111/j.1526-

[6] Headache: Hope Through Research [Internet] 2009 October [updated 2013 Nov 8; cited 2013 Dec 18]. Available from: http://www.ninds.nih.gov/disorders/headache/detail_hea dache.htm

[7] Jasvinder Chawla, MD, MBA. Migraine headache[Internet]. [updated 2013 Dec 3; cited 2013 Dec 18]. Available from: http://emedicine.medscape.com/article/1142556overview\#showall

\section{Volume 5 Issue 6, June 2016 www.ijsr.net}


[8] Bigal ME, Bigal JM, Betti M, Bordini CA, Speciali JG. Evaluation of the impact of migraine and episodic tension-type headache on the quality of life and performance of a university student population.Headache. 2001 Jul-Aug [cited 2013 Dec 8];41(7):710-9. Available from: http://www.ncbi.nlm.nih.gov/pubmed/11554960

[9] Sweileh WM, Sawalha AF, Zyoud SH, Al-Jabi SW, Shamseh FF, Khalaf HS. Epidemiological, clinical and pharmacological aspects of headache in a university undergraduate population in Palestine. Cephalalgia. 2010 Apr;30(4):439-46. doi: 10.1111/j.14682982.2009.01969.x.

[10] Menon B, Kinnera N. Prevalence and characteristics of migraine in medical students and its impact on their daily activities, Ann Indian Acad Neurol. 2013 Apr;16(2):221-5.doi: 10.4103/0972-2327.112472.

[11]Falavigna A, Teles AR, Velho MC, Vedana VM, Silva RC, Mazzocchin T, Basso M, Braga GL. Prevalence and impact of headache in undergraduate students in Southern Brazil.ArqNeuropsiquiatr. 2010 Dec [cited 2013 Dec 8];68(6):873-7. Available from: http://www.ncbi.nlm.nih.gov/pubmed/21243244

[12] Al-Tulaihi BA, Al-Jumah MA. Prevalence of migraine and non-migraine headache among high school students at the National Guard Housing in Riyadh, Saudi Arabia. Saudi Med J. 2009 Jan [cited 2013 Dec 18];30(1):120-4. Available from: http://www.ncbi.nlm.nih.gov/pubmed/19139785 Telephone, Inc. 